\title{
Distributed learning and management system for university courses
}

\author{
Sanna Liimatainen and Teemupekka Virtanen \\ Telecommunications Software and Multimedia Laboratory, Helsinki University of Technology, \\ Finland
}

\begin{abstract}
The Telecommunications Software and Multimedia Laboratory at Helsinki University of Technology provides several popular courses run by a limited number of staff. To manage the large number of homework assignments, we have developed a learning system which manages the administrative work. Students and staff do not have to be located in the campus area to use this system. In this paper we present the system and experiences we have gathered after using the system for some years.
\end{abstract}

Key words: learning system, course management

\section{INTRODUCTION}

This paper describes how course elements for students are managed in the basic courses of the Telecommunications Software and Multimedia Laboratory (TML) at Helsinki University of Technology (HUT). Our system is used in four of the largest and a few smaller courses where students have to complete homework assignments and pass an examination in order to get credits for the course. The homeworks, the possible programming assignment, and the examination are course elements. To handle the ever-growing amount of student work, we have developed a system to help manage the electronic mail and information about course elements for students. In their paper, Virtanen et al. (2002) say more about the courses and especially the computer examinations used in them.

The original version of this chapter was revised: The copyright line was incorrect. This has been corrected. The Erratum to this chapter is available at DOI: 10.1007/978-0-387-35615-0_52 


\section{TML LEARNING SYSTEM}

In our courses, we try to teach practice in addition to theory. Students learn better by doing or thinking by themselves. In order to pass our courses, students must do several homework and/or programming assignments. The completion of our course does not require physical attendance by students, only the examination needs to be done at the university. Assignments are returned by electronic mail. Because e-mail is easy to forge and to eavesdrop on, we use PGP to secure it (Zimmermann, 1994).

\section{THE STUDENT POINT OF VIEW}

All necessary information about students is collected at the sign-up for the course. In addition to common information, such as name and student ID number, we need their e-mail address and a public PGP key pair for each student. This has benefits and drawbacks: our work is minimal but students must get familiar with PGP and the basics of cryptology. The students' PGP public keys are stored in a public key ring provided by the standard PGP.

Students must authenticate their public PGP key by showing an identity or student card and by giving a finger print of their public PGP key to a course assistant. Authentication of the public PGP key is to check that the key belongs to the student, but only once in our courses if she does not change her PGP key.

The homework assignments are available on the course WWW pages, which is the easiest way to distribute them. Questions of homework assignments are not based only on the course book but also on 'the internet' and sometimes answering questions needs students to think a great deal for themselves. The student signs her answer text file with PGP and optionally encrypts it. The homework assignment answer is returned by sending it to the course e-mail address.

The TML learning system receives mail, checks signatures and decrypts mail. If everything checks, the system sends an acknowledgement back to the student. If not, a negative acknowledgement to clarify the problem is sent to the student, and she can try to resubmit her answer.

\section{ASSISTANT POINT OF VIEW}

All the electronic mail sent to courses' e-mail addresses ends up in the TML learning system where each course has its own mailbox. The messages area is also stored to a log file. Mail is sorted according to the sender and 
the subject (as follows). The homework returns and resulting submission emails are identified by their subject and handled separately. The homework returns are stored in a separate mailbox of the course where they can be distributed to assistants. The results are stored in the data base and the resulting message is acknowledged. If an assistant sends mail to the course e-mail alias, the system resends it to all the courses' assistants. If the sender is not one of the course staff, and the subject does not contain a key word, the electronic message ends up in the course mailbox.

Usually more than one assistant checks the returned homeworks of one homework round. Our system divides responses equally to the assistants and sends them to assistants by e-mail. The assistants check the answers according to the given model answer. They can comment on the work of the student. Because mistakes usually are similar, there are standard comments stored in the system, which can be referred to by symbols. There is also the possibility to write free-form comments if necessary. The assistant writes the results in a file, signs it with her PGP key, and sends it to the course email addresss. The system verifies the signature, sends an acknowledgement to the assistant, and results and comments to the students. The sending of examination results is similar.

In course mailboxes there are usually questions about the course from students. The responsibility for messages is given to a certain assistant, who identifies herself or resends it to another assistant. When responding to a message, a copy is stored in the log. Our system can also be used to send articles to a course's electronic news group.

\section{PROBLEMS OF THE TML LEARNING SYSTEM}

The biggest problem with the TML learning system is with the PGP key ring where about 6000 public PGP keys of the students are stored: from time to time it loses keys. Knowing when the key ring is broken is a big problem. It can only be detected when students complain that their homework assignment return has failed unexpectedly. We use the PGP key $\mathrm{ID}$ as the index of the database. If a student forgets her passphrase, she must create a new key pair (with a new ID). Then her homework answers are stored under two IDs. A minor problem is that all PGP versions are not compatible with the version we are using.

In the future the storage of PGP keys will be changed to being in a SQL data base and a new interface between the TML learning system and key handling will be written. The PGP key ID as the index of the data base must also be changed to the student ID number. 
In the computer science department at HUT a new common user interface for all departments' course element registers is under construction. This system will not provide secure electronic mail or the data base, but will demand changes to our TML learning system.

The identification of students will change if our university decides to use electronic identification cards provided by the state (see web-site). It uses X.509 certificates and a smart card to store the keys.

\section{CONCLUSIONS}

Despite some problems, the TML learning system has been successful. Students can do assignments where they want and return them electronically. Course staff can also do their work anywhere using the internet. Information is transferred in a secure way. Using this system it is easy to manage the workload of the staff. Assistants can do their work independently and the system combines the results and calculates the final grade.

There is still work to be done. The new version of key management is under construction and the data base also needs some modification. However, using this system we have managed to compensate for a lack of staff without decreasing the quality of our main duty - education.

\section{REFERENCES}

Väestörekisterikeskus. The Electronic ID Card. Available at: http://www.sahkoinenhenkilokortti.fi/default.asp?todo=setlang\&lang=uk (accessed on 7.1.2002)

Virtanen, T., Addams-Moring, R. and Staffans, L.A. (2002) Computerised Examination System. IFIP World Computer Congress, 2002, Montreal, Canada.

Zimmermann, P. (1994) PGP Users' Guide. Available at: http://www.tml.hut.fi/Opinnot/Tik$110.350 /$ Tehtavat/pgp/ (accessed on 18.10.2000)

\section{BIOGRAPHIES}

Sanna Liimatainen is a teaching researcher and her main research interest is computer security. Teemupekka Virtanen is acting as professor of computer security at HUT. 